\title{
Wilson's disease in an elderly patient
}

\author{
MaZiar Badi, Henry Wong mD, URs P SteinbreCher mD, Hugh J Freeman mD
}

\begin{abstract}
M BADII, H WONG, UP STEINBRECHER, HJ FREEMAN. Wilson's disease in an elderly patient. Can J Gastroenterol 1995;9(2):78-80. A 65-year-old man with Fanconi's syndrome was investigated for the cause of chronic liver disease. Wilson's disease was diagnosed based on the detection of bilateral KayserFleischer rings, a low serum ceruloplasmin level, increased urine copper excretion and positive histochemical stains of his liver for copper. This case is unusual because of the patient's elderly age at the time of diagnosis and the absence of neurological changes due to Wilson's disease in spite of advanced hepatic disease and the presence of Kayser-Fleischer rings. Even in the elderly patient, Wilson's disease should be considered a possible cause of chronic liver disease.
\end{abstract}

Key Words: Cirrhosis, Copper metabolism, Fanconi's syndrome, Hepatolenticular degeneration, Kayser-Fleischer rings, Wilson's disease

\section{Maladie de Wilson chez un sujet âgé}

RÉSUMÉ : Un homme de 65 ans atteint du syndrome de Fanconi a subi des épreuves afin d'identifier la cause de cette maladie hépatique chronique. La maladie de Wilson a été diagnostiquée sur la base de la présence d'anneaux de KayserFleischer bilatéraux, d'un taux de céruloplasmine sérique faible et de l'excrétion cuprique urinaire accrue, ainsi que de la coloration histochimique positive de son foie pour y dépister la présence de cuivre. Ce cas est inhabituel à cause de l'âge avancé du patient au moment du diagnostic et de l'absence de signes neurologiques attribuables à la maladie de Wilson, malgré une maladie hépatique avancée et la présence d'anneaux de Kayser-Fleischer. Même chez le patient âgé, la maladie de Wilson est à envisager comme cause possible de maladie hépatique chronique.

Is N 1911, WILSON DESCRIBED A "PURE syndrome of the corpus striatum" developing "always in young people" with a "constant presence of profound cirrhosis of the liver" (1). Since that time, Wilson's disease has been widely re-

garded as a disease whose initial manifestations almost always occur in individuals younger than 40 years of age. Young children typically present with liver disease, whereas in teenagers and young adults, neurological manifesta-

Department of Medicine (Gastroenterology), University of British Columbia, Vancouver, British Columbia

Correspondence and reprints: Dr Hugh Freeman, ACU F-137, Gastroenterology, Vancouver Hospital (UBC Site), 2211 Wesbrook Mall, Vancouver, British Columbia V6T 1W5. Telephone (604) 822-7216

Received for publication May 31, 1994. Accepted August 15, 1994 tions predominate (2). However, there are a few very rare case reports of Wilson's disease with apparent onset in late adulthood (3-7).

We report a male patient with Fanconi's syndrome who was first diagnosed with Wilson's disease at age 65 years after he presented for diagnostic assessment of chronic liver disease. The clinical diagnosis was based on the presence of bilateral Kayser-Fleischer rings, a decreased serum ceruloplasmin level, markedly elevated urine copper excretion and a liver biopsy staining histochemically positive for copper.

\section{CASE PRESENTATION}

A 65-year-old man with renal failure and Fanconi's syndrome was seen in January 1992 for investigation of chronic liver disease. In 1967, he developed a seizure disorder after sustaining a head injury with loss of consciousness; he was subsequently treated with phenytoin $200 \mathrm{mg}$ daily. Fanconi's syndrome was diagnosed in 1984 (at age 57) with a pattern of generalized amino- aciduria, hyperphosphaturia and osteomalacia. Liver disease was first identified at age 61 years when the patient presented with ascites. A liver biopsy was performed. This yielded a fragmented specimen that was reported to reveal fibrosis and 'pigmentation' but no specific diagnosis was established.

Because of his chronic liver disease and worsening ascites, the patient was referred for further evaluation. He complained of easy bruising, leg edema, 
weight gain of $14 \mathrm{~kg}$, anorexia and inability to concentrate. There was no history of risk factors for parenterally transmitted viral hepatitis or alcohol abuse. There was no family history of known liver disease or neuropsychiatric disorder.

His original liver biopsies were reviewed and the paraffin-embedded liver tissue blocks were reprocessed for histochemical stains; sections tested positive with orcein and rubeanic acid stains for copper.

Physical examination revealed a healthy appearing man with no clinical evidence of jaundice. Bilateral Kayser-Fleischer rings were visible to the naked eye and later confirmed on slit lamp biomicroscopy (Figure 1). Other less frequently reported ocular changes, ie, sunflower cataracts or an intraocular foreign body containing copper (chalcosis), were not seen. Neurological examination was normal except for slight right facial drooping. His abdomen was markedly distended with ascites. Peripheral stigmata of chronic liver disease were evident including spider nevi, gynecomastia, palmer erythema, multiple bruises and Dupuytren's contractures. Edema was present bilaterally to the midabdomen.

Laboratory investigations revealed (normal range in parentheses): hemoglobin $123 \mathrm{~g} / \mathrm{L}$ (140 to 180 ); white blood cell count $3.1 \times 10^{9} / \mathrm{L}$ (4 to $\left.11 \times 10^{9}\right)$; platelets $90 \times 10^{9} / \mathrm{L}(140$ to $\left.350 \times 10^{9}\right)$; serum creatinine $198 \mu \mathrm{mol} / \mathrm{L}$ (80 to 120 ); blood urea nitrogen 7.5 $\mathrm{mM}$ (2.5 to 6.8); alkaline phosphatase $95 \mathrm{U} / \mathrm{L}$ (30 to 110 ); aspartate aminotransferase $28 \mathrm{U} / \mathrm{L}$ ( 5 to 47 ); total bilirubin $17 \mu \mathrm{mol} / \mathrm{L}$ (2 to 23 ); international normalized ratio 1.5 (0.9 to 1.2 ); and serum albumin $36 \mathrm{~g} / \mathrm{L}$ (35 to 50 ). Serum copper was $16.0 \mu \mathrm{mol} / \mathrm{L}$ (normal 11.0 to 22.0) and serum ceruloplasmin was $75 \mathrm{mg} / \mathrm{L}$ (normal 150 to 600 ). Antinuclear and antimitochondrial antibodies were negative. Iron studies and alpha-1-antitrypsin were normal. Serological studies for hepatitis A, B and $\mathrm{C}$ were negative. Urine copper was $4.8 \mu \mathrm{mol} / 24 \mathrm{~h}$ (normal 0.5 to 0.9 ).

An abdominal ultrasound showed massive ascites and a small, nodular liver. Bile ducts were not dilated and

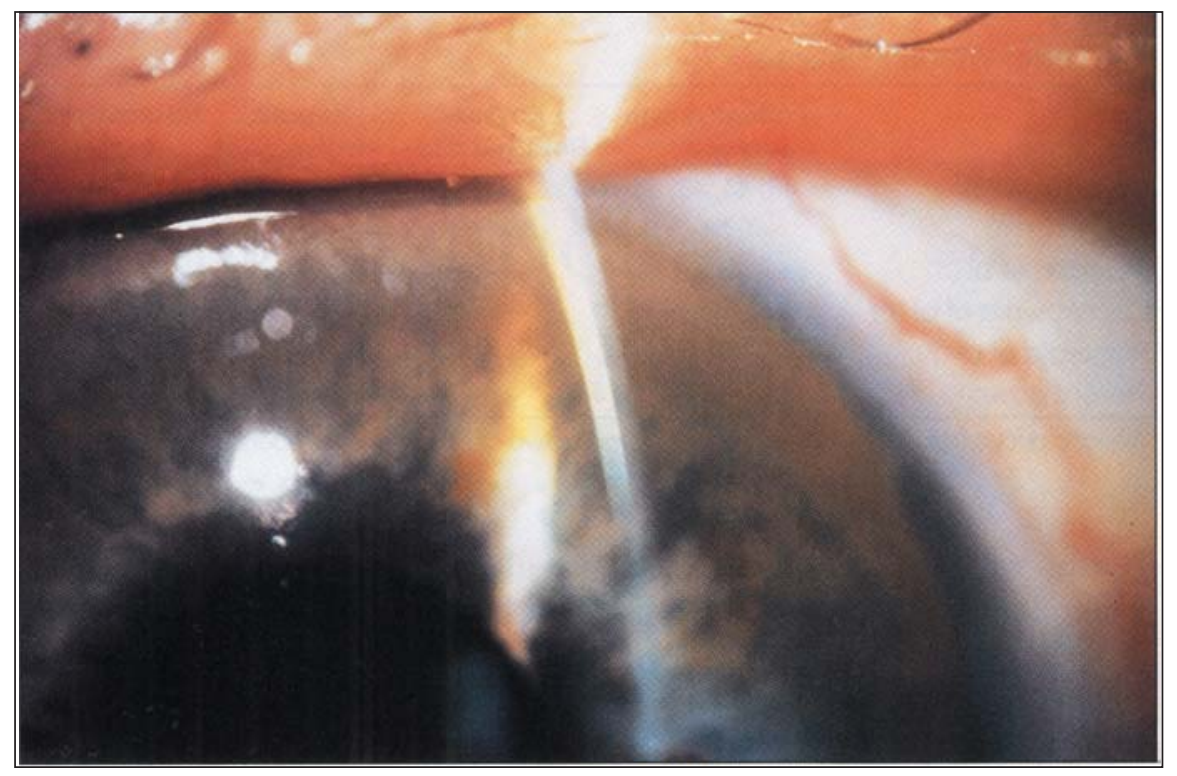

Figure 1) Kayser-Fleischer ring on peripheral region of cornea in patient with Wilson's disease. Other ophthalmological features found in Wilson's disease, such as sunflower cataracts, were absent

no gallstones were seen. A paracentesis revealed a transudate with negative cytology. Upper endoscopy revealed esophageal, but no gastric, varices. Computed tomography and magnetic resonance imaging of the brain showed generalized atrophy but no changes in the basal ganglia.

The patient was treated with penicillamine $500 \mathrm{mg}$ bid, and this increased his urinary copper excretion to $18.1 \mu \mathrm{mol} / 24 \mathrm{~h}$.

\section{DISCUSSION}

Different mechanisms have been implicated in the pathogenesis of Wilson's disease. The liver acts as a depot for copper. As the disease progresses, due to an inherited defect not yet completely understood, copper binding sites in the liver become saturated. This factor, along with direct hepatocellular damage, results in release of copper into the blood, which then proceeds to deposit in the cornea and basal ganglia (7). The reversal of abnormal copper metabolism in patients after orthotopic liver transplantation supports the critical role played in the pathogenesis of Wilson's disease by the liver.

Recent studies have provided data on the identification of the gene responsible for Wilson's disease, which has been identified on chromosome 13 . The gene product appears to be a copper-binding P-type ATPase protein and is apparently homologous to the Menkes disease gene (8). Mutation analysis has so far uncovered a number of disease-specific mutations, including transversions and frame shift mutations, affecting the Wilson's disease protein (8).

Many texts of general internal medicine assert that Wilson's disease is generally a disorder of patients younger than 40 years of age. It is believed that the hepatic form generally occurs in children while the neurological form is generally, but not exclusively, seen in older patients.

It has been stated that KayserFleischer rings and the neurological manifestations of the disease are invariably present together (2). The present case illustrates that these dicta are not necessarily true even though modern methods of imaging detection for central nervous system involvement in Wilson's disease were used in our patient, including computed tomography and magnetic resonance.

Despite his age of 65 , there is little question that this patient - with chronic liver disease and Fanconi's syndrome - had Wilson's disease. His diagnosis was based on a high urine copper excretion measurement, the presence of bilateral Kayser-Fleischer rings, a reduced serum ceruloplasmin level and 
TABLE I

Late onset Wilson's disease

\begin{tabular}{lcccc}
\hline Reference & $\begin{array}{c}\text { Patient(s) age } \\
\text { (years) }\end{array}$ & $\begin{array}{c}\text { Kayser- } \\
\text { Fleischer rings }\end{array}$ & $\begin{array}{c}\text { Hepatic } \\
\text { involvement }\end{array}$ & $\begin{array}{c}\text { Neurological } \\
\text { involvement }\end{array}$ \\
\hline Danks et al (3) & $43,44,48,58$ & - & + & - \\
Ross et al (4) & 58 & - & + & + \\
Madden et al (5) & 61 & + & + & + \\
Czlonkowska et al (6) & $41,43,45,47,53$ & + & - & - \\
Fitzgerald et al (7) & 55 & + & + & - \\
Present case & 65 & + & + & - \\
\hline
\end{tabular}

-Hepatic and/or neuropsychiatric features in one or two of five family members

positive orcein and rubeanic acid stains of the liver, along with the marked increase in excretion of copper following treatment with D-penicillamine. Table 1 tabulates and compares the clinical findings described in the literature to date; there are five earlier reports of patients with late onset Wilson's disease (3-7). Interestingly, in one report (6), an entire family of patients with late onset Wilson's disease is described suggesting that other factors, possibly genetic, may play a role in the time of clinical expression of the disease.

Our patient displayed no subjective or objective changes or manifestations of the neurological damage associated

\section{REFERENCES}

1. Wilson SAK. Progressive lenticular degeneration: a familial nervous disease associated with cirrhosis of the liver. Brain 1912;34:295-509.

2. Scheinberg IH, Sternleib I. Wilson's Disease. Philadelphia: WB Saunders, 1984.

3. Danks DM, Metz G, Sewell R, Prewett EJ. Wilson's disease in adults with cirrhosis but no neurological abnormalities. BMJ 1990;301:331-2.

4. Ross EM, Jacobson IM, Dienstag JL, Martin JB. Late-onset Wilson's disease with Wilson's disease. Diffuse brain atrophy seen on computed tomographs has been rarely described in Wilson's disease, but the characteristic changes that occur in the lentiform nuclei were absent in our patient (9). Similarly, Danks et al (3) and Fitzgerald et al (7) described patients with hepatic complications and no clinical evidence of central nervous system involvement, demonstrating that the hepatic form of Wilson's disease is not seen exclusively in children. Ross and colleagues (4) described neurological disease in the absence of Kayser-Fleischer rings, but our patient had prominent Kayser-Fleischer rings without neurological involvement, illustrating that parallel

with neurological involvement in the absence of Kayser-Fleischer rings. Ann Neurol 1985;17:411-3.

5. Madden JW, Ironside JW, Triger DR, Bradshaw JPP. An unusual case of Wilson's disease. Q J Med 1985;55:63-73. of Wilson's disease - report of a family. Arch Neurol 1981;38:729-30.

7. Fitzgerald MA, Gross JB, Goldstein NP, Wahner HW, McCall JT. Wilson's disease (hepatolenticular degeneration) of late adult onset. Mayo Clin Proc 1975;50:438-42.
6. Czlonkowska A, Rodo M. Late onset clinical expression of neuropsychiatric and ophthalmologic features in Wilson's disease are not always present.

The diagnosis in our patient was also supported by the concomitant presence of Fanconi's syndrome, a condition that has been previously recognized to be associated with Wilson's disease (10). Interestingly, in a recent report, patients with Fanconi's syndrome had onset of Wilson's disease approximately a decade later than those without Fanconi's syndrome (11). Factors that influence the time of clinical expression of this disorder are poorly understood and require elucidation.

Although it is not entirely clear if diagnosis will alter the course or clinical outcome of Wilson' disease in the elderly patient, we feel that the disorder deserves exclusion in the setting of undiagnosed chronic liver disease regardless of the patient's age. It is likely that treatment will result in an improvement in his renal status, disappearance of the Kayser-Fleischer rings and stabilization of his liver disease. Further follow-up in larger series of patients may provide additional data on the response to treatment in the elderly patient with Wilson's disease.

8. Chelly J, Monaco AP. Cloning the Wilson disease gene. Nature Genetics 1993;5:317-8.

9. Selekler K, Kansu T, Zileli T. Computed tomography in Wilson's disease. Arch Neurol 1981;38:727-8.

10. Uzman L, Denny-Brown D. Aminoaciduria in hepatolenticular degeneration (Wilson's disease). Am J Med Sci 1948;21 15:599.

11. Tesar V, Mokrejsova M, Marecek Z, Petrtyl J. Distal renal tubular acidosis in patients with Wilson's disease. Sb Lek 1991;93:315-23. (Abst) 


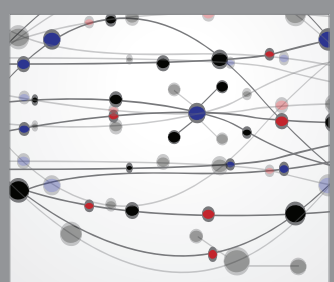

The Scientific World Journal
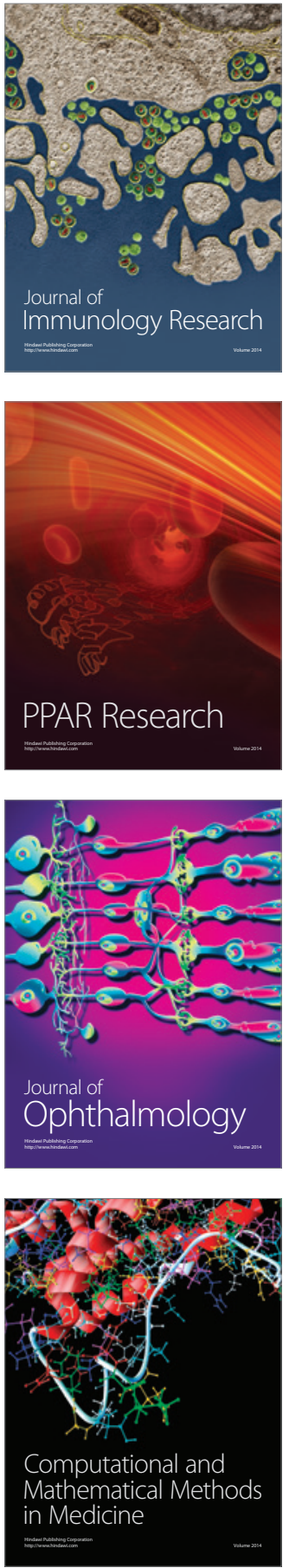

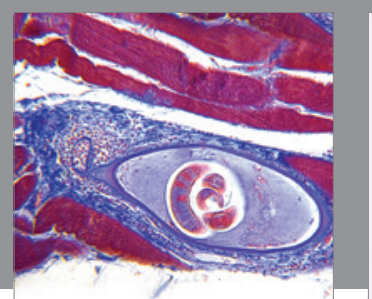

Gastroenterology Research and Practice

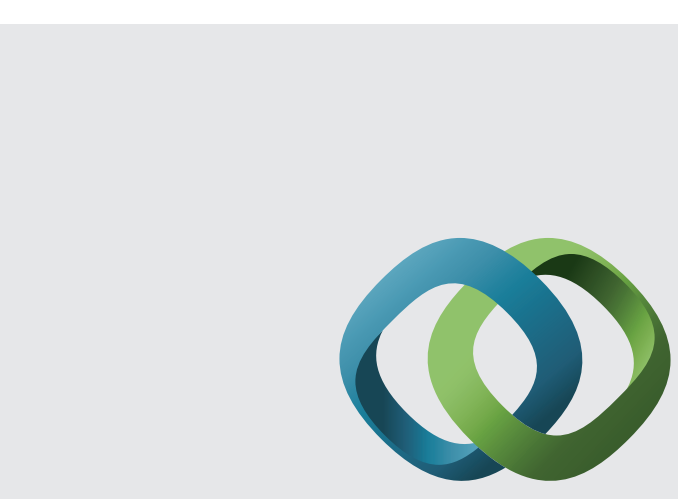

\section{Hindawi}

Submit your manuscripts at

http://www.hindawi.com
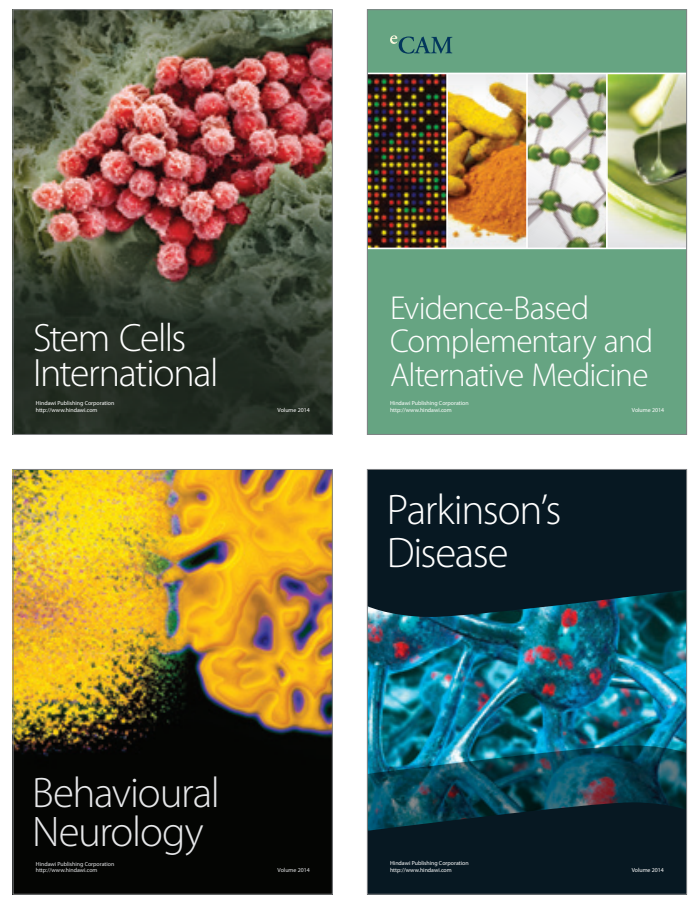
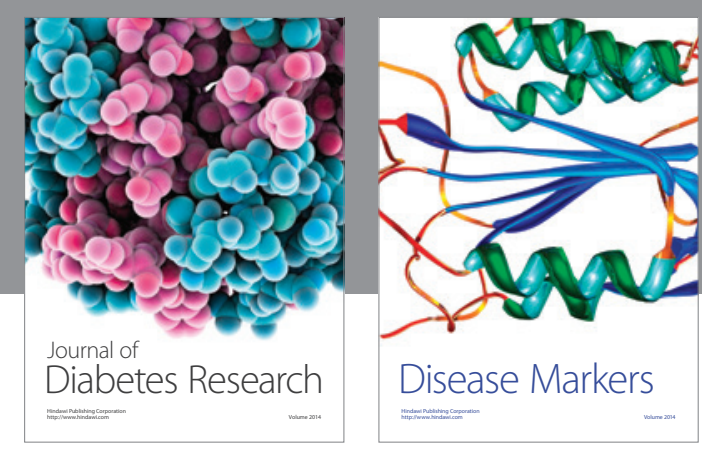

Disease Markers
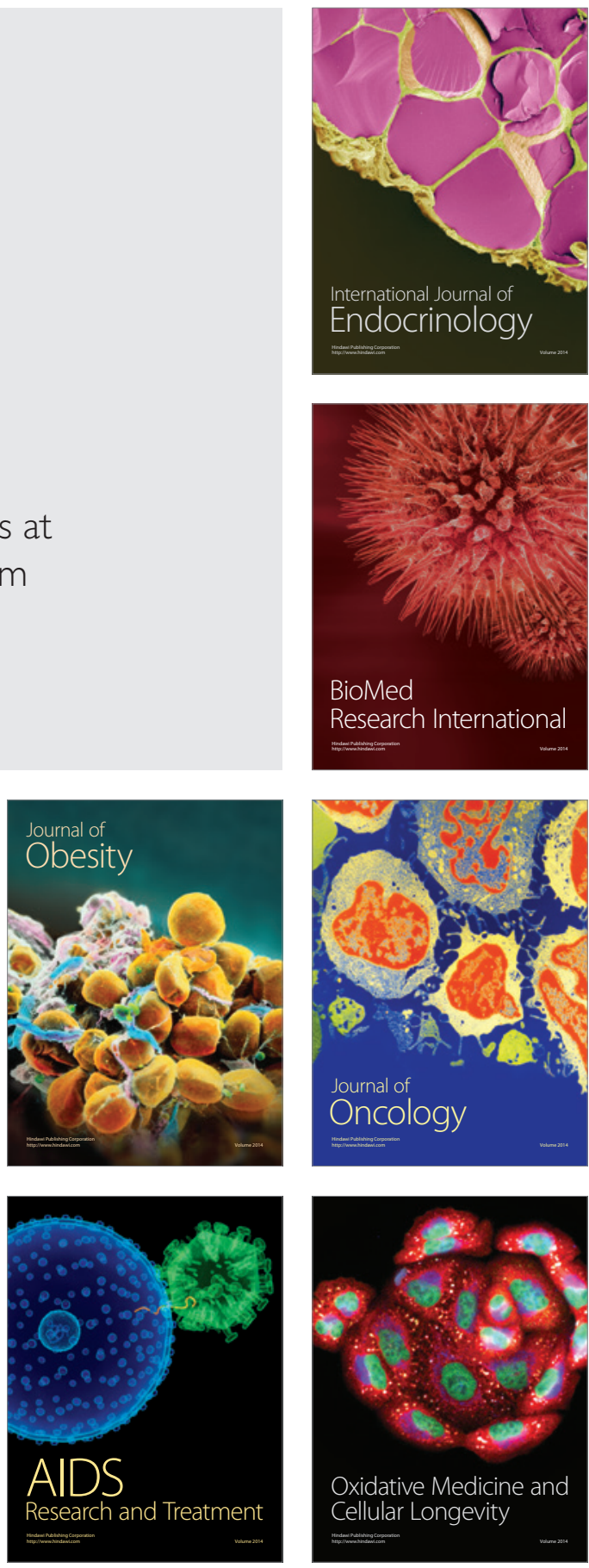